\title{
Etnografía de un forastero
}

JOHNNY PAYNE*

Volver en esta ocasión, con mis zapatos bien lustraditos, a unos cuentos quechuas que recopilé hace ya una década me provoca una mezcla extraña de placer y ansiedad, como si ocupara el lugar vulnerable del chiquillo en Cuentos Cusqueños que es bañado con jaboncillo, perfumado, y puesto en una cama nueva con antojos y dulces, para esperar la visita de una vaca mágica. $\mathrm{Al}$ chiquillo, fascinado y asustado a la vez, no le queda más que entregarse a lo que está por sucederle. El texto, narrado por Teodora Paliza, dice así:

A medianoche, desde la esquina: "Aaaa!" la vaquita comenzó a lamentar ... La vaquita seguía acercándose, acercándose, hasta la puerta de calle, y "Aaaa" lamentaba. Abrió la puerta lentamentef fentró despacito al cuarto. Velas lindas estaban «ärdiendou Olfareb̉i todoviorque estaba preparado, el sabor nomás. Cuando terminó, se acercó al lado del chiquito. Y con un chiiiu! se desprendió de su cuerito. Cuando se había desprendido, subió a un rincón del catre.

Cuando eché una mirada retrospectiva a estos cuentos cusqueños, se me ocurrió que valdría la pena narrar un cuento más, un cuento que no está incluido sino de forma indirecta en el tomo recopilado: me refiero al cuento del etnógrafo mismo. El objeto de escrutinio en las ciencias antropológicas suele ser las tradiciones de los indígenas, y queda sobreentendido que el folklorista mismo queda más o menos fuera del escenario, calibrando todo con sus instrumentos científicos. Pero ese forastero, al momento de entrar en el panorama con sus prejuicios y su manera inevitablemente peculiar de ver las cosas, deja

* Profesor de la Universidad de Northwestern (USA). 
de ser un medio transparente y neutral. Como dice el etnógrafo James Clifford, en un ensayo sobre autoridad etnográfica, "hay una poética de invención en todas las representaciones colectivas." Jamás se puede llegar al supuesto estado de la autoridad etnográfica absoluta, a un conocimiento pleno de los indígenas. Los tropiezos iniciales del investigador no son reemplazados por un caminar seguro y sagaz, como ha proclamado implícitamente el mito forjado por muchos resúmenes del trabajo de campo. El caminante queda, más bien, como se dice en quechua, thampithampi,tambaleante. Afirmando este hecho se rinde cuenta de la naturaleza incierta, subjetiva, y limitada de nuestra capacidad de conocimiento. Hoy les ofrezco, entonces, un cuento cuzqueño que se llama "Etnografía de un Forastero."

A los veintiún años, mocoso y barbudo, listo y preparado a medias, agarrado de una grabadora barata, me lancé sobre el Valle Sagrado de Los Incas a hacer eso que los expertos llaman etnografía. Agudamente consciente de $\mathrm{mi}$ inexperiencia y $\mathrm{mi}$ falta de credenciales antropológicas, me había empeñado, de manera condensada e intensiva, en profesionalizarme en lo posible. Un curso básico sobre Religiones Andinas, dado por Manuel Marzal en la Universidad Católica, iba a tener importancia más tarde cuando me puse a interpretar el contenido harto religioso $x_{1}^{\circ}$ sinçéćtico de dos cuentos secopilados- desde la leyenda del niño Jeșús que sada día hila la lana para el pastor jovencito para que puedan jugar juntos, hasta el chiste del cura viejo verde que se viste de San Pedro para poder hacer una visita nocturna a una monjita que sueña con sacar la vuelta a su "esposo" Jesús con su santo preferido.

Otro curso dado por otro profesor me rindió menos provecho. El siempre nos estaba hablando a los alumnos acerca del llamado sistema de los ceques, y de vasos comunicantes incaicos, y ninguno de nosotros en la clase teníamos la menor idea a qué se refería. Creo que ceques, $\mathrm{c}-\mathrm{e}-\mathrm{q}-\mathrm{u}-\mathrm{e}-\mathrm{s}$ son divisiones conceptuales del imperio incaico, aunque hasta la fecha no puedo decir ni eso con seguridad. Cuando los estudiantes, tomando juntos un café una tarde en la cafetería, especulamos sobre ese misterio, resultó que todos nosotros siempre le oíamos decir al profesor "ejes," en vez de "ceques", y alguien sugirió que tal vez los "ejes" pertenecían a los carros de fuego en que los 
condenados siempre llegaban -pues hasta un carro de fuego en algo tenía que rodar. Por eso de los vasos comunicantes, algún vivo sonriente en la mesa sugirió que los chasquis sedientos tal vez habían tomado sus inca kolas de esos vasos cuando llegaba cada uno a su punto de transmisión y descando. En nuestras conversaciones, el imperio pronto se derrumbó.

Pero más que en los cursos formales, mi ardor por el folklore primero fue inspirado por mis lecturas nocturnas de Arguedas, a la luz eléctrica siempre vacilante de Lima. Mildred Merino de Zela me dio consejos y me permitió pasar horas y días estudiando las leyendas, de ortografías idiosincrásicas, inciertas, $\mathrm{y}$ a veces casi ilegibles, archivadas en la biblioteca del Instituto Riva Agüero. Sus páginas amarillentas me hacían estornudar en el silencio cavernoso de esa casona, pues siempre he tenido una alergia horrible al polvo. Admiraba igualmente las tradiciones orales en otros libros recientes y de moda en ese tiempo, y que aún no tenían encima su capa de polvo. Mis libros preferidos eran, y siguen siendo Gregorio Condori Mamani, recopilado por Ricardo Valderrama y Carmen Escalante, y Kay Pacha, recopilado por Bernabé Condori y Rosalind Cow, y mi fantasía desde el principio fue lograr una recopilación equivalente a las suyas. Con esa aspiración, me fui al Cusco a armarme con dos meses intensivos de estudio de la lengua quechua, ofrecido por et Instituto de Pastoral Andina. El Instituto daba esos cursos gecada año especialmente para sus agentes pastorales, pero permitía que un forastero de vez en cuando ingresara. Cuando llegué a la Casa de Retiro una tarde de fango y lluvia, no me tenían en la lista, pues mi confirmación de matrícula no les había llegado, pero el asunto pronto se arregló y me fui a dormir a las tres de la tarde, casi desmayado por el oxígeno escaso y las colinas interminables.

Aunque chancaba duro día y noche, asistía asiduamente a las charlas sobre realidad andina, y visitaba ruinas poco conocidas los fines de semana como Piki Llaqta, el pueblo de las pulgas, y por fin logré pronunciar esa maldita oclusiva glotalizada post-velar sorda, que se deletrea q apóstrofo, y se dice q', q'enti, q'asa, picaflor y quebrada, aún no tenía la menor idea por dónde iba a empezar las labores que me había propuesto. Los demás participantes en el cursillo tenían 
tareas legítimas a las cuales se dedicaban durante el resto del año en Los Andes, de desarrollo tecnológico y espiritual, y yo en cambio era de verdad un forastero, en el fondo poco diferente a los turistas que congregaban en la llamada "Calle Gringo", comiendo pizza, comprando cocaína, y haciendo las veces de indio grotescamente paródico con sus ojotas y chompas típicas, sus fajas tejidas y sus bolsas rellenas de hojas de coca y trozos de cal. La realidad surandina que supuestamente me rodeaba, los picaflores, y las quebradas que veía a diario, y esa de que hablaban en las charlas, me parecía más remota que nunca.

Mi primer vínculo con el mundo autóctono se me vino encima del rincón menos esperado. Así sucede siempre en los cuentos cusqueños, sean modernos o antiguos, como ese de la joven hermosa que se disfraza de vieja patera hasta que un joven en la casa donde ella duerme bajo las escaleras y trabaja de patera se enamora de ella. Ella misma le dice "Cómo puede un niñito quererme a mí, una vieja lagañosa, de esa manera? Está haciendo bailar mucho a mi bastón." Sus hermanos antes del matrimonio también dicen: "Qué horrible! Nuestro hermano se va a casar con esta vieja fea de corazón viejo." Pero en eso, el novio mismo entró, "y puso el vestido hermoso, como una flor, a la novia. La chica se veía hermosísima." Los quechuahablantes aprendieron hace siglos los disfraces que han tenido que asumir para que el restoldeltmundo aprenda-âteconocerlos tal como son. Las máscaras quelès bailarines sé ponen en Semana Santa o en las fiestas patronales pueden ser espantosas, como esas de la diablada, o provocar risa, como esas narices enormes del baile Los Majeños, donde se satiriza a los comerciantes arequipeños que se enriquecieron de la mano de obra campesina. Pero en cualquier de los casos, el yeso de todas aquellas máscaras baratas vendidas en las tiendas, clavadas en la pared detrás de la Inca Kola, siempre contiene una pizca de ironía. Es un elemento esencial de la sobrevivencia quechua.

Un día, tres tipos de aspecto campechano entraron a la Casa de Retiro donde yo estudiaba el pasado pluscuamperfecto y la primera persona genérica, echado sobre el pasto húmedo, bajo un sol de febrero loco que achicharraba mi cara pálida. Oiga usted, mister, dijo uno de ellos. Estamos tratando de comprar unos autobuses de Los Angeles, California, para la Cooperativa de Transportes en nuestro pueblito. 
Qué tal si usted traduce la llamada telefónica? El hecho de que los ángeles que les tenía encantados a estos supuestos campesinos moraban no en el hanaq pacha, el cielo indio, como me había asegurado el profesor Marzal, sino en California, me provocaba dudas acerca de la utenticidad de los tres señores. No había podido dudar más si me hubieran dicho que eran Los Tres Reyes Magos. Pero al menos ellos me habían asegurado que vivían en un pueblito, y acepté mi rol de traductor.

Ellos, por su parte, no me desilusionaron completamente; para agradecerme, después me invitaron a participar en una lindación ardua de las fronteras de su comunidad, donde tomamos aguardiente de una quena, y ellos amontonaron piedras al borde de sus terrenos para indicar lo suyo. Unas semanas después me confesaron que habían llevado, el día de la lindación, una caja de medicamentos porque quedaban seguros que me iba a desmayar en el camino. Cierta forma del machismo -la capacidad de aguantar-tiene suma importancia en el surandino, y aunque nosabía esø de los medicamentos, me di cuenta en el momento mismo de trepar las colinas que me estaban poniendo a una prueba de hombría, como cual aspirante a la mano de la hija del hacendado.

Miguel Wamáß̧iunlơ dedes cọmuneros gue llegaría a conocer sumamente bien, cuentada histeriade esahijas ba hija del hacendado, después que se muere su padre, anuncia que se casará con la persona que le acompañe adónde sea que vaya. "Adonde vaya, tienes que seguirme... Lo que yo coma, comeremos juntos." Dos enamorados ricos le aceptan, y ella les lleva uno por uno al panteón al canto del pueblo. Cuando ella está por abrir la puerta del panteón, cada enoamorado se escapa gritando. Por fin, el hijo del mayordomo le acepta, y le acompaña mientras ella abre el panteón con su llave.

Clac! Lo abrió. Yél, todvía a su lado, no la sol tó. Ella tenía una llavecita en su bolsa, una pequeña llavecita... la llavecita del nicho era pequeñita... Y abrió el bocanicho, que tenía una rejita. Después de abrirlo, ella sacó un lavador de asado. Lo sacó y cac! rompió la carne. Le dio un brazuelo entero al joven. El joven también, a todo dar, empezó a comer. Era pues, rico asado de cordero. Volvieron al pueblo al amanecer, y en seguida se casaron. 
Miguel Wamán termina el relato diciendo que con tales pruebas, "así se conoce la debilidad de un hombre."

Habiéndome casi acabado con esa lindación, ellos nos invitaron a mi esposa y a mí a comer un cuy asado formidable, con choclo, quesillo, rocoto relleno, pan, papas a la huancaína. Sentado entre ellos en una mesa larga, con lavadores de comida y con tragos calientes especialmente preparados en casa, el licor zumbando en mi cabeza, soltando una lengua trabada por el estudio constante y abstracto del quechua, pude cultivar el sentido efímero, borracho y falso de ser él que ganó a la hija del hacendado por su perseverancia.

Dentro de poco tiempo, me había mudado a su pueblo, San Jerónimo, a probar una realidad menos heoica y más monótona. Pasé unos meses ayudándoles a algunos comuneros a cavar pozos y sembrar maíz, tomando chicha agria y horrible, pagando precios de mercado negro para comprar mi Quáker diario en la tienda de la esquina, y esperando con una paciencia obligatoria el momento propicio para recopilar un cuento o siquiera una adivinanza. Muchas personas nos trataban cordialmente a mi esposa y a mí, y hasta con calor, pero no se presentaba la ocasión netamente folklórica que era mi meta. Me agripaba cada quince dias por bañarme con una manguera chorreando agua heladísima, que hacía que un vapor se formara alrededor de mi cuerpo tiritante, como run almrina arrancadaversolel susto. Comencé a darme cuenta de por qué los surandinos dividían las enfermedades en calientes y frías. Cuando no tenía gripe, acompañaba a los comuneros cuando iban a sus terrenos, los observaba, y a veces participaba en sus labores. Realmente les ayudé muy poco en esas jornadas, pero me permitieron ofrecer esos gestos simbólicos como evidencias de mi ineptitud en cosas de agronomía, y de mi buena voluntad en cuestiones de amistad.

A veces se burlaban ferozmente de mí en un quechua que aún entendía a medias. Preguntaban, cuando me veían cocinar y lavar ropa en mi cuarto alquilado, si acaso no hubiera comido demasiado dulce de chico. A mi mujer, cuando se enteraron que no teníamos niños, le decían "mula." Aún circulaban rumores de que éramos cocaineros del tipo que se veía en la Calle Gringo del Cusco, pues 232 
no se sabía de qué plata vivíamos, y la palabra "beca" no tenía sentido concreto para ellos. Los comuneros veían esa clase de "jipi internacional" de la Calle Gringo con el más fuerte desprecio, y así como yo seguía considerándolos con rezagos de mis preconcepciones iniciales, ellos tampoco pudieron abandonar por completo los folklorismos que quedaban en su actitud hacia mí. Varios entre ellos quedaron convencidos de que yo tenía riquezas secretas, y me visitaban de vez en cuando en mi cuarto para proponer proyectos y planes que generalmente tenían que ver con detectores de metales preciosos y cosas por el estilo. En esos planes, siempre me proponían a mí como el inversionista.

Pero por fin, el comunero que llegó a ser uno de mis informante más prolíficos y simpáticos, Miguel Wamán, seguramente tomó piedad de mí, y me invitó a su casa a comer. Esa noche tomamos un montón de cerveza y aguardiente, y con su esposa y su hija de diez años metidas bajo las frazadas, y yo sentado al pie de la cama, Miguel se puso a contarme adivinanzas. Me hablo de sus padres, ya muertos hace tiempo, y comenzó a cantar en su voz permanentemente ronca una canción acerca de un huérfano: Noqa pobreqa, mana taytayoq, wakchaschallay; mana piniyoq wakchaschallay. A pesar de los cincuenta años de diferencia.en nuestras edades, más las diferencias notables de clase y cultura, nos hicimos grandes patas en poco tiempo. Los otros comuneros se burlaban de él al comienzo cuando nos veían caminando juntos en la calle a cada rato.

Miguel había trabajado duro a través de los años -primero como albañil de casas, después como obrero en la Cervecería Cusqueña, y por último como comunero después de la reforma agraria. Ya tenía setenta años. Pero a pesar de su ambición, no era de esos que les llaman en el surandino "ambiciosos." Tenía pocas preocupaciones de cómo los demás lo veían, y no le interesaban para nada los chismes. Escéptico en cuestiones de religión, mezclando libremente su quechua y su castellano hablado, y capaz siempre de adaptarse a las exigencias nuevas con una falta de resistencia sorprendente, él sin embargo se sentía muy seguro de su identidad cultural de quechua-hablante. Cusco hace siglos había dejado de ser el ombligo del mundo, pero Miguel quedaba centrado en sí con una tranquilidad admirable. 
Si digo que él estaba contento con el lugar que ocupaba, no quiero decir que aceptaba la marginalidad oprimente que seguía siendo su herencia. Pero tampoco tenía ni ilusiones milenarias ni corazón tacaño. Estaba construyendo una segunda casa, muy lentamente, en su poco tiempo libre, y a veces me despertaba temprano para ir a hacer adobes con él. Al mismo tiempo, él solía o "sabía", como dicen allá, trabajar en ayni. Los comuneros habían repartido entre sí, en parcelas particulares, la mayoría de los terrenos un tanto rocosos otorgados por la reforma agraria, y Miguel, como los demás, se dedicaba mayormente a lo suyo. Pero él también labraba el llamado terreno cooperativo la parcela en el valle que fue poseída en común. Lo labraba de buena gana y sin codicia, pero también sin participar en la fantasía dudosa de que esa cooperativa modesta, supuestamente anti-capitalista, consituía en lo más mínimo un nuevo imperio campesino.

Lo que sí quiero decir es que Miguel, uno de los espíritus más dulces y más puramente quechuas que conocí en mi tiempo allí, vivía netamente los preceptos esbozados por el folklore cusqueño. Como dije, él no era ambicioso. Cuando pienso en él, siempre pienso en el trabajador del relato "La Ninfa de la Vilcanota", que Miguel me contó. Ese trabajador pobre, que mantiene a su familia cortando leña, no tiene nada más en el mundo que su hachita Uln día el hachass cae al río Vilcanota, y cuando él se lamenta su pérdida, una ninfa sele le aparece del agua. Ella le muestra dos hachas, una de plata y otra de oro, pero él contesta que no son suyas. Entonces, "ella una vez más volvió al agua, y sacó la pequeña hachita del leñador. "Esta es tu hacha?" En eso, dice Miguel,

Ay, tususpa yaqaraq wañurun! "Hachachaymi, hachachaymi mamita!"

"Kayqa respondesuyki, mana ambisiosochu kasqanki.

Respondesunki kay qori hachapuwan, kay qolqe hachapuwan, kay hachachaykipuwan."

En español, diríamos:

Ay, el leñador casi murió bailando! "Mi hachita, mi hachita mamita!"

(y ella le contesta:) "Esto te correponde por no haber sido ambicioso. Te corresponden esta hachita de oro, esta hachita de plata y tu propia hacha." 
Pero este relato de riquezas repentinas tampoco permite demasiadas ilusiones. Termina por contar como los parientes del leñador, codiciando su fortuna, le dan de comer carne de perro para fastidiarlo. Recuerdo que un día, cuando volví a San Jerónimo después de haber estado en Bolivia por una semana, Miguel me informó que los comuneros de la cooperativa, que se llamaba Chimpawaylla, habían peleado a causa de unas quejas acerca del repartimiento de los terrenos particulares. El no había participado en esa pelea, y me contó con tristeza y amargura como los comuneros habían comenzado a tirar piedras, los unos a los otros, y que resultaron varios heridos.

A pesar de su dulzura temperamental, Miguel también poseía esa chispa de pícaro que he dicho forma parte esencial de la resistencia cultural del mundo quechua. Por eso un día él también decidió, cuando menos lo esperaba yo, tomarle el pelo al gringo forastero. Cuando fuimos a visitar el ataúd de su madre, Miguel me ofreció como represco una botella del agua salada y bendita que la iglesia vendía en el Día de los Muertos. Sin saber qué cosa era, bebí de la botella, y cuando hice una mueca horrible $\gamma$ escupi una bocanada del agua salada al suelo donde yacía la madre de Miguel, él se rompió a carcajadas y gritó "Orines del cura!"

En ese tiempo, Rènílícecopiladoseunabbuena parte de los cuentos que Miguel sabía, y aưnque segúán falltando otros narradores dispuestos y capaces, otras formas de participación en la vida cultural del pueblo se presentaron, a veces de manera inesperada. Una pareja de San Jerónimo que se iba a casar nos invitó a mi esposa y a mí a ser padrinos de aros en su boda. El servicio de matrimonio, leído por un cura monótono, anciano, serio, y más flaco que el Jesús a quien servía, fue de esa especie de catolicismo severo que se desarrolla para protegerse del sincretismo subversivo y pagano, con sus múltiples caras amenazantes de saqra, gentil y condenado, que sigue echándole a la religión católica en el surandino. Al final del matrimonio, la pareja hizo bautizar a su niño en la capilla. Pues todo el mundo por ahí sabe lo que puede suceder al fruto de las relaciones no consagradas. Teodora Paliza cuenta la historia de un niño que nació de una chica violada por su padre, y de la madre quien, sin saber la gravedad del pecado, intenta el remedio ortodoxo pero tardío: 
"Qué voy a hacer con esta chola? Quién es el padre? Dime." Su mamá le interrogaba entre lapos, pero la chica no habló. El niño estaba llorando feo. Ese mismo rato los gatos comenzaron a lamentar: ¡ñau, ¡ñau, ¡ñau, ¡ñau, ¡ ñau." La mujer dijo: "Y por qué está llorando este niño? Debe ser por su bautizo. Vamos pues. Lo llevaremos a ser bautizado." La mamá de la chica puso un pañalcito, un gorrito, y una camisita al niño, y lo llevó. El niño seguía llorando. Estaban por entrar en la iglesia. Pero el niño se murió.

Felizmente, nada semejante sucedió en el ritual alegre en que participamos mi esposa y yo. El niño bonito y plácido fue bautizado en la pila, y todos fuimos en seguida a la casa de los padres de la esposa, donde se presentó una verdadera orgía de comida, trago, y música, que duró por dos días sin par. Los platos de yuca, qowi kanka, carne asada, cancha, y quesillo que nos sirvieron a los padrinos fueron como para reventar la barriga con sólo mirarlos. Los dos nuevamente casados bailaron primero. Entonces, yo bailé con la esposa, y mi mujer con el esposo. Después ella con el padre de la esposa, y yo con la madre. Y así sucesivamente. No kabía techo en el lugar donde nos divertíamos bajo las estrellas. Había llovido chorros durante el día, volviendo la tierra un fango, y mientras bailábamos waynos y rompetablas, y mientras das campesinasdel tutgar, con su pañuelos bien agarrados, se empeñatongen tiraimel lálCsuele, el barro hondo volaba por todas partes bajo nuestros tacones, embarrando a los puros y a los pecadores por igual.

Si esta charla fuese realmente un cuento cusqueño, con mucho gusto me dejaría a mi mismo allá bajo las estrellas, salpicando con la tierra de San Jerónimo mi propio cuerpo y los cuerpos de los seres humanos alrededor mío. Quedaría por fin integrado al mundo andino, unido a la tiera y al cosmos, al ukhu pacha, al kay pacha, y al hanaq pacha. Pues los cuentos quechuas de hecho a menudo se terminan con una boda, y el narrador termina el cuento con un guiño vivo al oyente, diciendo "Yo también estaba allí en el matrimonio, y te iba a traer un asado rico. Pero atrás había unos perros bravos, y me lo quitaron."

Pero el observador-participante, como es forastero, sigue siendo tanto observador como participante. Esa dinámica, como dice Clifford, 
"es una dialéctica experiencia e interpretación," de manera que la autoridad etnográfica no puede residir con comodidad ni en la uno ni en la otra. Hasta aquí se puede entrar en la cosmovisión indígena pero no más allá, como se pensaba en la visión romántica del mundo que dio lugar a la etnografía como disciplina, y a la costumbre sospechosa de referirse a las sociedades indígenas como "primitivas." Sea cual fuera nuestro nivel de conocimiento de la realidad andina, y a pesar de nuestras buenas intenciones, es difícil evitar la tentación de expropiar el terreno espiritual andino, de querer hacerlo falsamente suyo. Ninguno de nosotros, los no-andinos, puede ocupar el lugar del chiquillo perfumado que espera la vaca mágica, ni otorgar así nomás al exombligo del mundo el ilustre de un lugar ideológicamente privilegiado. Ya en 1929, José Carlos Mariátegui, en su "El problema de las razas en América Latina" había tomado conciencia de eso cuando advirtió:

Del prejuicio de la inferioridad de la razón indígena, empieza a pasarse al extremo opuesto: el de que la creación de una nueva cultura americana será esencialmente obra de las fuerzas raciales autóctonas. Suscribir esta tesis es caer en el más ingenuo y absurdo misticismo. Al racismo de los que desprecian al indio, porque creen en la superioridad absoluta y permanente de la raza blanca, sería insensato y peligros oponer ell racismoedealos que superestiman al indio, con la fe mesiánicgeenusucimisión comor raza en el renacimiento americano.

La cuna del primero de esos dos racismos íntimamente relacionados, es dibujada con astucia por Alfredo Bryce Echenique, en su novela satírica Un Mundo Para Julius. El chiquillo perfumado y engreído, en este caso, se llama Julius, y en él se imagina que su empleada india personal "debe descender de algún indio noble, un inca, nunca se sabe. La chola que podía ser descendiente de un inca, sacaba a Julius cargado en peso de carroza, lo apretaba contra unos senos probablemente maravillosos bajo el uniforme, y no lo soltaba hasta llegar al baño del palacio, al baño de los más pequeños, sólo de Julius, ahora." Cuando le recoge para este baño diario, ella parece ser, como lo diría Vallejo, una mujer de senos apacibles. Ella se incorpora fácilmente al resto de ese mundo de fantasías, carente de amenaza, del hijito alegremente ensimismado de los super-ricos. 
Y a eso de las seis de la tarde, diariamente, la chola hermosa cogía a Julius por las axilas, lo alzaba en peso y lo iba introduciendo poco a poco en la tina. Los cisnes, los patos y los gansos lo recibían con alegres ondulaciones sobre la superficie del agua calientita y límpida, parecían hacerle reverencias.

Juliucito, heredero del mundo, conquistador por excelencia y en pequeño, manso demoledor de las piedras de Machu Picchu, tanto quisiera conocer un verdadero inca. Aunque pareciera un sacrilegio decirlo, no quedan más que dos o tres pasos de esa actitud hasta el canto simpático, complejo, lleno de compasión, pero también mesiánico de Pablo Neruda en Alturas de Machu Picchu:

Sube a nacer conmigo, hermano.

Dame la mano desde la profunda zona de tu dolor diseminado...

Yo vengo a hablar por vuestra boca muerta.

A través de la tierra juntad todos

los silenciosos labios derramados

y desde el fondo habladme toda esta larga noche

como si yo estuviera con vosotros anclado.

A pesar del gesto de arrogarse la voz indígena colectiva, el poeta no está, a fin de cuentas, con ellos anclador y el hablar por bocas muertas siempre tiene algo de yentriloquia En el Perú, el indigenismo ha tomado muchas formas que comparten ese error que dice Mariátegui de superestimar al indio, con fe mesiánica, desde algunos movimientos guerrilleros vanguardistas que les sacan la mugre a los indios mientras proclaman que los Incas eran socialistas en embrión y que sus descendientes formarán una dictadura del proletariado, hasta las muchas revistas literarias y cosmopolitas que tomas al indio como simple punto de referencia, para evocar en sus carátulas la esencia efímera e impresionista de pueblos indios lejanos.

Pero no es mi propósito negar el valor que puede haber en el intento de aproximarse a lo surandino, especialmente cuando el intento logra divorciarse en lo posible del mesianismo de que habla Mariátegui. Negar ese intento sería repudiar los tres años de mi vida que dediqué a la recopilación, la traducción, y el análisis de Cuentos Cusqueños. Como he dicho, el entrenamiento profesional antropológico en sí no 
es un remedio total para el indigenismo romántico, y hasta puede dar al investigador un sentido falso de su objetividad. Como lo ha comprobado Bryce Echenique con su visión satírica y eficaz, hasta algunos habitantes de las tribus que pueblan las Avenidas Salaverry de este mundo son capaces de pensar bien la cuestión indígena, aplicándole una mezcla de autocrítica, perspicacia e imaginación controlada. Dio la casualidad el año pasado, cuando estaba en la Universidad de Stanford, en California, que me pidieron ser el profesor de Quechua del sobrino de Alfredo Bryce. Ese sobrino, Iñigo, me impresionó mucho siendo en casi todo el sentido lo opuesto de un Julius; él a fondo la historia del Perú autóctono y moderno. El verano anterior, siguiendo mi recomendación, él se había ido a estudiar el quechua en el Cusco con una de mis profesoras antiguas. Pero a diferencia de mí a su edad, él tiene una conciencia de lo andino no sólo apasionada, pero también admirablemente sistemática y, como dicen en las universidades, bien formada. Esa formación es, a la vez, su ventaja formidable y el riesgo que corre. Me parecía tener encima de eso algo de la imaginación y el escepticismo echeniquianos para templar su profesionalización incipiente y la ilusión dada por su "disciplina" de que podrá abarcar y dar cuenta de todo esa combinación de dones, llegue a ser un historiador o antropólogo enérgico, cauteloso, serio, satírico y sensible-justo lo que hace falta en ell estudio del surandino.

El mismo Mariátegui, con su método cuidadosamente histórico y materialista, no puede dejar por completo de reconocer, y hasta alabar, una subjetividad fuerte que necesariamente acompaña el intento de elaborar un esquema adecuado de la vida indígena. En uno de sus primeros escritos, "El Alma del Tawantinsuyo," una reseña sobre el libro De la Vida Inkaika, por Luis Valcárcel, Mariátegui sucumbre de buena gana al lirismo de su tema. Dice con entusiasmo que en el libro de Valcárcel

late una emoción persistente e idéntica, así cuando su prosa es poemática como cuando es crítica, contiene los elementos de una interpretación total del espíritu de la civilización incaica... En las páginas del escritor se siente, ante todo, un hondo lirismo indígena. Este lirismo de Valcárcel, en concepto de otros comentaristas, perjudicará tal vez el valor interpretativo 
de su libro. En concepto mío, no. No sólo porque me parece deleznable, artificial, y ridícula la tesis de la objetividad de los historiadores, sino, porque considero evidente el lirismo de todas las más geniales reconstrucciones históricas. La historia, en gran proporción, es puro subjetivismo y, en algunos casos, es casi pura poesía.

Suscribo a grandes rasgos esta tesis polémica de Mariátegui, aunque esta fe en un lirismo redentor, como la actitud científica a que se opone, me parece demasiado optimista y mesiánica. El lirismo puro, así como la supuesta objetividad, bien puede distorsionar la realidad andina. En el caso mío, el proceso fue mayormente uno de descartar ciertos aspectos de la visión poética que guiaba mis interpretaciones y acciones. El sueño de que mi entrada a la madera indígena, "con mi razón apenas, con mis dedos," podría ser rotunda, fue el error previsible que tenía que cometer el forastero. Después de casi siete meses de vivir en San Jerónimo, había recopilado entre quince y veinte cuentos de Miguel Wamán, más algunas adivinanzas y canciones suyas. Otros dos o tres habitantes me habían contado cosas, pero de manera muy parcial, o en español, pero realmente aparte de mi amistad con Miguel, no parecía tener grandes posibilidades, a corto plazo, de ensanchar mis investigaciones. El tiempo iba quedando corto y y comenzé a sentir algo de pánico.

De vez en cuandosolíavisitán, elh eldnstituto Nacional de Cultura del Cusco, a Antuka Vegacenteno, una antropóloga ilustre con largos años de experiencia, y charlábamos de mi trabajo, o del suyo, o de temas generales de la antropología. Ella me recomendaba lecturas y me prestó los apuntes de un curso que ella había dictado. En fin, muy generosamente me iba dando una formación informal. Cuando me quejé de la suerte limitada que seguía corriendo en San Jerónimo en la recopilación de cuentos, ella me consideró en frío por un momento con sus ojos simpáticos, y me dijo unas palabras fatalmente sencillas. "Johnny", dijo Antuka, "por qué sigues pensando tú que el folklore tan sólo se encuentra en los lugares rurales? No sé cómo te has metido en la cabeza esa idea. El folklore existe en todas partes: el Cusco mismo está lleno de cuentos, y toda clase de gente los sabe contar." No sé si ella había querido decirme eso ya hace tiempo, y estaba esperando que yo iniciara la ocasión propicia, o si simplemente me 
había tomado por más inteligente y sofisticado de lo que realmente era.

En todo caso, para mí fue un relámpago. Me puse a pensar esa misma noche embrolladamente, pero también con algo de nueva lucidez entre mis meditaciones turbias. Pero, claro, hasta mis profesoras de quechua deberían saber cuentos. Y no era cierto, como yo mismo había observado más de una vez, que San Jerónimo estaba en fuertes vías de urbanización y transición, y que la forma de pensar de sus habitantes estaba muy influida por el hecho de que muchos de ellos trabajaban de taxistas o guías turísticos en el Cusco, o en el caso de los jóvenes, porque asistían a la Universidad del Cusco Toda la zona del Cusco y sus alrededores realmente formaba una sola configuración cultural. Ese proceso de urbanización era, en realidad, la clave a una comprensión adecuada de la situación campesina.

Los próximos tres meses, de diciembre hasta comienzos de marzo, cuando volví a los EE.UU., fueron tres de los más ocupados de mi vida entera. Mi esposa y yo hábíamos comenzado a trabajar enseñando inglés en un instituto en el Cusco, porque la plata de la beca nos iba quedando corta. Ahí conocí a un lingüista quien me dijo que sabía de un cuarto vacío que se podía alquilar de unas personas muy buena gente en el Barrio Magisterio. Nos mudammos ał Gusco a comienzos de enero, a esa casa, doñde givía una viudade sesenta y tantos años, con su hija y su nieta. Eso fue una de las casualidades más felices de nuestro tiempo en los Andes, pues esa dueña de casa era Teodora Paliza, quien tenía una habilidad formidable de narrar cuentos quechuas. Ella y yo de inmediato nos llevamos sumamente bien. Pasamos largas horas juntos en su bodega oscura, hablando en un quechua que yo por fin manejaba bastante bien. Aun cuando charlábamos en español, si entraba alguien a la tienda para hacer compras, ella me hacía cambiar repentinamente al quechua, sólo para que ella pudiera disfrutar las miradas de susto que eso provocaba en sus clientes, cuando veían un gringo barbudo y flaquísimo tomando un Inca Kola y hablando pesadamente el runasimi, la lengua de la gente. Cuando salían de la bodega con sus bocas aún abiertas, ella casi se moría de risa.

Una de mis alumnas en el curso de inglés trabajaba de Hostess en el Hotel Libertador, y me dijo que si yo le enseñaría villancicos 
navideños en inglés, ella me contaría en quechua un bonito relato del niño Jesús que le había enseñado su abuela de Ollantaytambo. Como estaba por terminarse la temporada navideña, eso quería decir también que el curso anual de quechua en el Instituto de Pastoral Andina estaba por comenzar. Una amiga alemana que había ingresado al curso tenía que viajar a Chile, y ella me regaló el primer de sus dos meses del curso intensivo. En vez de repasar gramática quechua, aproveché de esas sesiones para que algunas de mis profesoras del año pasado me contaran relatos y me ayudaran con la transcripción de las cintas de Miguel Wamán. En otro momento, fui al Concejo de San Sebastián para escuchar cuentos de unos obreros que estaban reparando una calle allí.

En fin, había montones de oportunidades, y recopilé la mayoría de mis Cuentos Cusqueños en el espacio de un par de meses. La sierra estaba, pues, de nuevo en el poqov, en la época de lluvias, el tiempo de fermento y madurez. Si en el año desde que había llegado a la sierra surandina, me había acostumbrado al oxígeno escaso, esta vez casi me desmayé por falta de dormir día tras día; tan incesantemente trabajaba. Pasé las pocas horas que me quedaban libres en la biblioteca del Centro Bartolomé de Las. Casas, tratando de formar un esquema al menos rudimentario de la.información copiosa que se me vino encima. Una temporada larga de preparaciones inciertas estaba dando un fruto inesperado, y ya teria suficientes conocimientos de la cultura de la zona como para hacer algunos apuntes preliminares hacia una interpretación.

Pero aunque esta metáfora de temporadas recurrentes me sirve ahora, como buen cuentista, para cerrar mi cuento cusqueño, no sería preciso dar la ilusión que había llegado a una madurez definitiva, así como lo puede hacer un choclo o una papa. Mi cambio de táctica representó un reconocimiento implícito de que una de las cosas principales le da el poder de resistencia e integridad continuada a una cultura, es su capacidad de dar entrada selectiva y tan sólo parcial a los forasteros. Por más que la cultura quechua poseyera una unidad subyacente, todo esquema que yo elaborara de la zona cuzqueña no podría ser sino fragmentario. Ese esquema tendría sus aciertos innegables, y yo lo situaría lo más cuidadosamente posible dentro de mis 
observaciones etnográficas concretas, y los textos mismos, y el marco teórico sugerido por el proceso de urbanización y sincretismo cultural que estaba experimentando la zona. Pero mi análisis y presentación del proyecto sin duda terminaría siendo, como decía Mariátegui, una reconstrucción subjetiva con un lirismo evidente -en fin, la interpretación de un forastero.

Dos cuentos que me fueron narrados por Miguel Wamán captan bien la paradoja de mi estadía en San Jerónimo. Uno se llama "El Gringo Burro", el otro "Lo que el Gringo Comió", y eran cuentos que él obviamente había reservado, dado su tema, hasta un momento en que nos conocimos muy bien, para que no me ofendiera demasiado por el contenido. Así como la broma de los orines del cura que me hizo en el ataúd de su madre, estos chistes eran también a la vez una burla y un gesto de confianza. Señalaban en un solo gesto la intimidad profunda que yo había logrado con él, pero también los límites necesarios e infranqueables entre los indigenas y los forasteros, impuestos por una historia feroz de culturas antagónicas y los forasteros. Me contó "Lo Que El Gringo Comiô" una noche después de haberme invitado a comer mote y papas amontonadas en una frazada en su casa, cuando descansamos a ta luz de las velas, frotándonos las barrigas. El cuento va así:

Dice gue un gringo yenía a caballo. Una señora estaba vendiendo apanado de rana, bien preparadita. El gringo comió dos o tres platos, hasta satisfacerse. "Qué rico mamita!" Qué rico que comió! Después de comer, se fue en su caballo. Mientras iba, vio cualquier cantidad de sapos amontonados en el río. El gringo los cogió hasta llenar su alforja. Entonces el gringo llegó a la casa donde estaba alojado.

Prendió su pequeño primus, y apanó el sapo con harina. Lo frió y comió el asado. Pero después de comerlo, en la noche, se puso grave. El gringo estaba mal. Cuando estaba por morir, llamó a la dueña de casa, la dueña misma del alojamiento. "Mamita, ya me voy!"

La dueña dijo: "Ah, que se vaya nomás! pues si es que me está pagando. Yo ni loca me voy a levantar. Así que sea; que se vaya."

Nuevamente la llamó. "Mamita, ya me voy!" 
"Caramba! Yo qué voy a hacer? Que no me pague."

Por última vez la llamó. "Mamita, ya me voy!"

"Vete nomás pues!" En la mañana, la dueña del alojamiento se levantó. Y cuando se levantó, el caballo del gringo todavía estaba allí. Resulta que el gringo estaba muerto. La dueña del alojamiento se quedó con toda la plata del gringo. Hasta se quedó con su caballo, y no había nadie para reclamar por el gringo.

Miguel me ofreció ese cuento sin más comentario, sólo con una carcajada y una sonrisa de buen compañero, bajo sus ojos levemente irónicos. Esa noche él hizo las veces del etnógrafo. Me demostró en breve que el indígena, lejos de ser el objeto pasivo de investigaciones ajenas, ha ido por mucho tiempo elaborando su análisis propio de la dinámica del contacto entre culturas. Entre los muchos cuentos vitales que el informante tiene en teserva, reside con todos sus detalles iluminantes, la etnografia de un forastero.

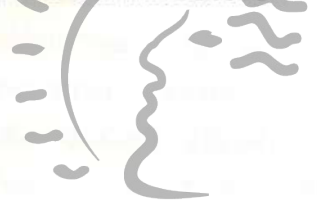

\section{Biblioteca de Letras "Jorge Puccinelli Converso»}

